\title{
The Impact of Breast Cancer on Female Sexuality: An Integrative Literature Review
}

\author{
Ana Rita P Castelo ${ }^{1}$, Mônica Oliveira B Oriá ${ }^{1}$, Anne Fayma L Chaves ${ }^{1}$, Karine C Bezerra ${ }^{1}$, Ana Fátima C \\ Fernandes ${ }^{1}$, Camila Teixeira M Vasconcelos ${ }^{1} \&$ Camila B Moreira ${ }^{1}$ \\ ${ }^{1}$ School of Nursing, Federal University of Ceará, Fortaleza, Brazil \\ Correspondence: Camila B Moreira, School of Nursing, Federal University of Ceará, Fortaleza, Ceará, 60.430-160, \\ Brazil. Tel: 1-604-360-2150. E-mail: camilabrasil@alu.ufc.br
}

Received: January 17, 2017 Accepted: February 15, 2017 Online Published: February 28, 2017

doi:10.5539/gjhs.v9n5p180 URL: https://doi.org/10.5539/gjhs.v9n5p180

\begin{abstract}
Objective: The aim of this study was to conduct an integrative literature review on the impact of breast cancer (CA) on female sexuality.

Methods: The search was performed online in November 2014 using the following databases: Cumulative Index of Nursing and Allied Health Literature (CINAHL), Scopus, PubMed, Latin American and Caribbean Health Sciences (LILACS) and the Cochrane Library. The search results consisted of 13 articles.

Synthesis: Most studies have shown that women have less lubrication and a decrease in desire, which directly affect their quality of life. Moreover, $70 \%$ of the articles described limitations of the studies, the most cited of which were as follows: small sample size because of the feeling that participants considered the theme to be embarrassing, the altered emotional state decreased willingness to participate in the study, and the non-participation of husbands in the study reduced the impact on marital intimacy.
\end{abstract}

Conclusion: It can be concluded that breast cancer has a negative impact on the sexual function of women who are affected by this disease.

Keywords: sexuality, breast cancer, women's health, review, nursing

\section{Introduction}

Cancer (CA) is a chronic degenerative disease that is considered a public health problem due to the high morbidity and mortality as well as the changes that various treatments may cause on the physical, psychological and social aspects, and finally, on sexuality, which is not any less impactful(Brazil, 2011; Brazil, 2014).

The treatment of this pathology primarily involves mastectomy and chemotherapy, and approximately $50 \%$ of women survive for at least 15 years after diagnosis. Surviving this disease means adjustments to new conditions, which can be hindered by physical consequences due to mastectomy. Patients may also experience psychological changes, such as loss of self-esteem, depression, feelings of guilt, failure and sexual problems, since according to some studies, about $40 \%$ of women with breast cancer experience some sexual dysfunction (e.g., reduction in lubrication, desire and orgasm)(Ferreira et al., 2013; Lewis et al., 2004; Vieira et al., 2013).

Sexuality encompasses the behaviour related to a person's sexual identity and comprises sexual relations between individuals. Sexual dysfunctions are problems that occur in one or more phases of the sexual response cycle; these include lack, excess, discomfort and/or pain with respect to the expression and development of these phases, which manifest in a persistent or recurring manner (Brazil, 2010).

The patient's health condition can affect many aspects of sexual function that are important in relation to nursing care and its resultant effects on the patient. A recent study showed that sexuality is a profound, comprehensive and coherent part of one's personality and is the core basis of one's sense of health and attitude towards oneself (Rashidi \& Dashti, 2016). Other studies have shown the importance of sex life and emotional quality of life of women with breast CA, especially in their resilience and survival (Hill et al., 2012; Letourneau et al., 2012).

In this context, it is essential that health professionals focus their care on the sexual health of women with breast CA, since this aspect may influence their quality of life. Due to the importance of this subject, the scientific 
literature offers a large number of studies. Therefore, this study aimed to present an integrative review of the literature on the impact of breast CA on female sexuality. Consequently, this study also aimed to contribute to the planning and operations of the care of the sexuality of women with breast CA.

\section{Method}

The present integrative literature review adhered to the following steps described by Whittemore and Knafl (Whittemore \& Knafl, 2005): 1. Identification of the research question; 2. Methods search to identify relevant studies; 3 . Selection of the study; 4. Charting of the data and collating, summarizing, and reporting of the results.

\subsection{Identification of the Research Question}

In November 2014, a literature search was conducted to answer the following question: What is the impact of breast cancer on female sexual function?

\subsection{Methods Search to Identify Relevant Studies}

To achieve more precise results, the literature search was performed independently by two reviewers, who used the same databases and search terms. After the searches, no disagreements arose, and therefore, a third reviewer was not needed.

Five databases were evaluated: Cumulative Index of Nursing and Allied Health Literature (CINAHL), Scopus, PubMed, Latin American and Caribbean Health Sciences (LILACS) and the Cochrane Library. The search was performed using the keywords mentioned below as well as their Farsi equivalents. Medical Subject Headings terminology (MeSH) was used where possible (in PubMed), and keywords used in those databases were not used in Medical Subject Headings terminology. The search terms were as follows: "Sexual Dysfunction Physiological" and "Breast neoplasms." Articles were included if they addressed the subject of sexual dysfunction and breast cancer, if they were were classified as an original research article and if they were published in English, Spanish or Portuguese. Duplicate publications were excluded.

The total number of articles in the literature is summarized in Table 1, but only 13 were considered relevant to the guiding question.

Table 1. Selection of the articles according to the inclusion criteria

\begin{tabular}{lllllll}
\hline \multirow{2}{*}{ Criteria } & \multicolumn{2}{l}{ Databases } & & & \\
\cline { 2 - 7 } & PubMed & CINAHL & LILACS & Cochrane & Scopus & Total \\
\hline Total articles found & 88 & 03 & 01 & 02 & 105 & 199 \\
Delete per language & 19 & 00 & 00 & 00 & 05 & 24 \\
Delete per abstract & 41 & 01 & 00 & 00 & 26 & 68 \\
Repeated & 00 & 01 & 00 & 02 & 67 & 70 \\
Does not approach the study theme & 17 & 01 & 01 & 00 & 05 & 24 \\
Total selected & 11 & 00 & 00 & 00 & 02 & 13 \\
\hline
\end{tabular}

\subsection{Data Collection and Analysis}

The 13 selected studies were analysed and synthesized according to some characteristics such as identification of the study, objectives, methodology, results and conclusions. In the analysis and subsequent synthesis of the articles that met the inclusion criteria, we used a summary table specially built for this purpose, which included the following relevant aspects: type of study; type of breast CA diagnostic methods used to evaluate sexual dysfunction, type of sexual dysfunction, sexual dysfunction and implications of the return to sexual activity after breast cancer. 


\section{Results}

Through an analysis of the 13 selected articles, it may be observed in Table 1 that most of the articles were published in 2011 (40\%), followed by the year 2013 (23\%) and $2008(20 \%)$. With regard to the origin of the publications, international studies prevailed. This finding shows that the issue of sexuality and breast cancer affects individuals worldwide, but also that this issue has become important at the national level.

With regard to the design of the studies, all studies were quantitative. The design of the analysis is paramount, considering that this allows us to see the perspective in which the problem was analysed. As for the location of the studies, $90 \%$ were conducted in health care systems (primary, secondary and tertiary), and only one of the studies was conducted elsewhere (conference against breast cancer). The limitations of the studies were described in $70 \%$ of the articles, and the most cited were as follows: small sample number because of the feeling that participants considered the theme to be embarrassing, an altered emotional state decreased the willingness to participate in the study, and the non-participation of husbands in the study reduced the impact on marital intimacy. As shown in Table 2, the studies revealed the impact of breast CA on the sexual function of affected women.

Table 2. Analysis of studies according to aspects that are relevant to the impact of CA on female sexual function

\begin{tabular}{|c|c|c|}
\hline Variables & $\mathrm{N}$ & Reference (sample number in each study) \\
\hline \multicolumn{3}{|l|}{ Type of study } \\
\hline Quasi-experimental & 01 & Jun et al., 2011 (45 women). \\
\hline Cohort & 03 & $\begin{array}{l}\text { Cavalheiro et al., } 2012 \text { ( } 48 \text { women); Panjari, Bell, \& Davis, 2011(1684 women); Yang } \\
\text { et al., } 2011 \text { ( } 243 \text { women). }\end{array}$ \\
\hline Cross-sectional & 09 & $\begin{array}{l}\text { Andersen, } 2009 \text { ( } 69 \text { women); Barni \& Mondin, } 1997 \text { ( } 50 \text { women); Broeckel et al., } \\
2002 \text { ( } 76 \text { women); Herbenick et al., } 2008 \text { ( } 118 \text { women); Juraskova et al., } 2013 \text { ( } 35 \\
\text { women); Kedde et al., } 2013 \text { ( } 45 \text { women); Safarinejad M, Shafiei, \& Safarinejad S, } \\
2013 \text { ( } 186 \text { women); Sbitt et al., } 2011 \text { ( } 120 \text { women); Takahashi et al., } 2008 \text { (124 } \\
\text { women). }\end{array}$ \\
\hline \multicolumn{3}{|c|}{ Time of Diagnosis of breast cancer } \\
\hline$<5$ years & 12 & $\begin{array}{l}\text { Andersen, 2009; Barni \& Mondin, 1997; Cavalheiro et al., 2012; Herbenick et al., } \\
\text { 2008; Takahashi et al., 2008; Jun et al., 2011; Juraskova et al., 2013; Kedde et al., } \\
\text { 2013; Panjari, Bell, \& Davis, 2011; Safarinejad M, Shafiei, \& Safarinejad S, 2013; } \\
\text { Sbitt et al., 2011; Yang et al., 2011. }\end{array}$ \\
\hline$\geq 5$ years & 01 & Broeckel et al., 2002. \\
\hline \multicolumn{3}{|c|}{ Instruments used to measure Sexual Dysfunction } \\
\hline FSFI & 04 & $\begin{array}{l}\text { Cavalheiro et al., 2012; Juraskova et al., 2013; Safarinejad M, Shafiei, \& Safarinejad } \\
\text { S, 2013; Sbitt et al., } 2011 .\end{array}$ \\
\hline SFQ & 03 & Broeckel et al., 2002; Herbenick et al., 2008; Panjari, Bell, \& Davis, 2011. \\
\hline CARES & 01 & Jun et al., 2011. \\
\hline $\begin{array}{l}\text { Questionnaire developed by } \\
\text { the researcher }\end{array}$ & 05 & $\begin{array}{l}\text { Andersen, 2009; Barni \& Mondin, 1997; Kedde et al., 2013; Takahashi et al., 2008; } \\
\text { Yang et al., 2011. }\end{array}$ \\
\hline
\end{tabular}




\section{Type of Sexual Dysfunction}

Decrease in desire

Reduction of excitation

Reduction of lubrication

Reduction of orgasm

Reduction of satisfaction

05

Increase in pain

Barni \& Mondin, 1997 (64,0\%); Broeckel et al., 2002 (35,0\%); Jun et al., 2011(55,6\%); Panjari, Bell, \& Davis, (71,7\%), 2011; Safarinejad M, Shafiei, \& Safarinejad S, 2013 (42,5\%); Sbitt et al., 2011 (64,0\%); Takahashi et al., 2008 (49,3\%); Yang et al., $2011(30,1 \%)$.

Broeckel et al., 2002 (28,0\%); Cavalheiro et al., 2012 (33,3\%); Kedde et al., 2013; Safarinejad M, Shafiei, \& Safarinejad S, 2013 (37,0\%); Sbitt et al., 2011 (38,0\%); Yang et al., $2011(13,3 \%)$.

Barni \& Mondin, 1997 (42,0\%); Broeckel et al., 2002 (35,0\%); Cavalheiro et al., 2012 (33,3\%); Herbenick et al., 2008 (66,7\%); Jun et al., $2011(61,1 \%)$; Juraskova et al., 2013 (88,0\%); Safarinejad M, Shafiei, \& Safarinejad S, 2013 (57,0\%); Sbitt et al., 2011(54,0\%).

Barni \& Mondin, 1997 (44,0\%); Broeckel et al., 2002 (22,0\%); Cavalheiro et al., 2012 (25,0\%); Herbenick et al., 2008 (37,2\%); Kedde et al., 2013(64,0\%); Panjari, Bell, \& Davis, 2011 (72,5\%); Sbitt et al., 2011(40,0\%); Takahashi et al., 2008 (28,8\%).

Andersen, 2009 (32,0\%); Cavalheiro et al., 2012 (45,5\%); Jun et al., 2011(47,1\%); Safarinejad M, Shafiei, \& Safarinejad S, 2013 (53,8\%); Sbitt et al., 2011 (37,0\%).

\begin{tabular}{|c|c|c|}
\hline & & $\begin{array}{l}(85,0 \%) \text {; Herbenick et al., } 2008(35,0 \%) \text {; Juraskova et al., } 2013(92,0 \%) \text {; Sbitt et al., } \\
2011(65,0 \%) \text {; Takahashi et al., } 2008(24,7 \%) \text {. }\end{array}$ \\
\hline \multicolumn{3}{|l|}{ Dysfunction Implication } \\
\hline Marital relationship & 03 & Broeckel et al., 2002; Herbenick et al., 2008; Takahashi et al., 2008. \\
\hline Quality of life & 10 & $\begin{array}{l}\text { Andersen, 2009; Barni \& Mondin, 1997; Cavalheiro et al., 2012; Jun et al., 2011; } \\
\text { Juraskova et al., 2013; Kedde et al., 2013; Panjari, Bell, \& Davis, 2011; Safarinejad M, } \\
\text { Shafiei, \& Safarinejad S, 2013; Sbitt et al., 2011; Yang et al., 2011. }\end{array}$ \\
\hline \multicolumn{3}{|c|}{ Return to sexual activities after breast cancer } \\
\hline$<6$ months after surgery & 01 & Takahashi et al., 2008. \\
\hline$\geq 6$ months after surgery & 09 & $\begin{array}{l}\text { Andersen, 2009; Cavalheiro et al., 2012; Jun et al., 2011; Herbenick et al., 2008; } \\
\text { Juraskova et al., 2013; Kedde et al., 2013; Panjari, Bell, \& Davis, 2011; Safarinejad M, } \\
\text { Shafiei, \& Safarinejad S, 2013; Yang et al., 2011. }\end{array}$ \\
\hline
\end{tabular}

Legend: (FSFI) Female Sexual Function Index, (SFQ) Sexual Function Questionnaire, (CRESQ) Cancer Rehabilitation Evaluation System Questionnaire.

\section{Discussion}

In addition to the problems related to sexual health, other problems faced by women who undergo mastectomy are intensified by factors from the disease itself; this does not diminish the need to strengthen health actions aimed at minimizing the sexual discomforts that these women experience.

The finding that the included articles present $100 \%$ of the items using quantitative methods deserves attention. These studies motivate discoveries that provide rationale and validation in clinical practice that may lead to modifications of aspects of that practice. The study design analysis is important because it demonstrates how the problems were analysed (Pinto et al., 2014). Knowledge in the quantitative field results from observation, measurement and interpretation of objective reality (Drienssnack, Sousa, \& Mendes, 2007).

Human sexuality is a complex phenomenon with many dimensions, and it is not a concept that can be considered a separate type of health, as it consists of a central factor in the maintenance of patient welfare. In contrast, the treatment of breast cancer may affect the sexuality of women, and therefore, it becomes necessary to change the practice of clinical care (Ferreira et al., 2013).

Female sexual dysfunction was detected by various instruments. Among them is the Female Sexual Function Index (FSFI), which was originally developed (Rosen et al., 2000) with an overall Cronbach's alpha for the six areas 
equal to 0.82. This instrument has been used in Brazil (Hentschel et al., 2007; Pacagnella, 2009; Thiel et al., 2008) and has shown Cronbach's alpha equal to $0,94,0,96$ and 0,95 . This revealed the homogeneity of the scale and the test-retest reliability as assessed by the intraclass correlation coefficient, which resulted in identical values $(1,00)$ (Thiel et al., 2008). This instrument is a concise, valid and reliable tool that is used to measure female sexual function and can be easily applied to women of a wide age range by many professionals.

The types of sexual dysfunction that primarily affect women who undergo mastectomy were found to be reduced lubrication, orgasm and desire. In a study of several groups of women, one consisting of women with breast CA and the other of menopausal women, all of whom received chemotherapy, and another study, which featured women without cancer and postmenopausal women, the FSFI scale was used to evaluate sexual dysfunction. It was observed that patients who received breast CT showed a decline in the lubrication $(\mathrm{p}=0,03)$ and satisfaction $(\mathrm{p}=$ 0,018) domains compared with before treatment(Blumel et al., 2004). This demonstrates the effects that the treatment of breast CA may exert on the sexual lives of these women; these problems may occur because chemotherapy treatments cause vaginal dryness, which leads to dyspareunia during sexual intercourse. In addition, the mastectomy procedure is a mutilating surgery that leads to reduced self-esteem, which interferes directly with satisfaction and sexual desire (Ferreira et al., 2013; Vieira et al., 2013).

In a study of young women diagnosed with breast cancer (mean age was 37,4 years) and women without cancer, in order to evaluate their experience with orgasm, it was noted that young breast cancer survivors scored significantly lower in the subscale of orgasm on the Sexual Function Questionnaire (QFS) compared with women without cancer. This difference can be explained by a number of reasons, including changes related to hormone treatment, fatigue, vaginal dryness, dyspareunia, anxiety and stress, body image, the ability to relax during sex, interest and desire (Herbenick et al., 2008).

In addition, multiple studies have shown the results of the use of the FSFI in the general population. One study consisted of a survey conducted in Chile, which included $40 \%$ of women with sexual dysfunction, while another study in the United States included $43 \%$ of women with sexual dysfunction (Abdo, 2004). The prevalence of sexual dysfunction is high and ranges between 25 and 63\% worldwide (Ribeiro, Magalhaes, \& Mota, 2013). According to one literature review, the prevalence of sexual dysfunction in women was $40-45 \%$ (Lewis et al., 2004), while a study in Brazil revealed that half of the women reported some form of sexual difficulty(Pablo \& Soares, 2004).

In a study of 346 women in Portugal, the prevalence found in the DSF was 77,2\% (IC 95\% 72,0-82,7). The disturbance of orgasm was the most prevalent form of dysfunction and was reported by $55,8 \%$ of women (IC $95 \%$ $51,0-63,9)$. Out of the factors associated with this issue, stress was the most prevalent $(30,7 \%)$. Dyspareunia was the second most reported by women (40,9\%, IC 95\% 35,6-49,0)(Santos \& Vieira, 2011).

It became evident from the analysed studies that breast cancer has a direct association with sexual dysfunction and leads to a significant reduction in the quality of life of these women when they are not offered appropriate psychological support, whether it be from family members or from health professionals who are able to offer this support. A study conducted in Morocco, which included 120 women treated in an oncology department, showed that $90 \%$ of women complained of sexual dysfunction after they underwent chemotherapy; moreover, $100 \%$ of those women had not received information from health professionals about sexual function-related effects caused by treatment for breast cancer (Sbitti et al., 2008).

A recent systematic review showed that younger women who undergo chemotherapy report concerns about menopause, fertility, body image and sexuality. Addtionally, our partners reported that breast cancer leads to a reduction in conjugal and family involvement (Fobair \& Spiegel, 2009). In a study of 50 Israeli men whose wives had been diagnosed with breast cancer, $75 \%$ of men noticed changes in their relationship, and over one-third experienced reduced marital communication (Holzner et al., 2001; Kadmon, Ganz, \& Woloski-wruble, 2008; Sadovsky et al., 2010).

Thus, support from spouses may play an important role in the sexuality of women with breast CA. The advent of this cancer can strengthen some relationships but have negative effects on other aspects of life, and often, women experience difficulty discussing feelings or even the perception of their loss of femininity (Huguet et al., 2009). Partners may be directly affected by the disease because a sensitized woman with a changed body image may become distant from her companion.

Some studies in the literature have reported the interruption of sexual activity for at least one year, with an 
assessment that even five years after surgery, sexual life does not return to normal(Moura, Silva, \& Oliveira, 2010). However, according to a study of 135 women conducted in São Paulo, half of the women experienced a return to sexual activity within six months after diagnosis. About half of these women had an active sex life and had sex an average number of six times per month. It was also observed that age was a factor that was associated with reduced sexual activity in women with breast cancer $(\mathrm{OR}=0,9 ; \mathrm{p}=0,05)$ and that women in a stable relationship were 63 times more likely to have an active sex life $(p<0,05)$ (Vieira et al., 2013).

Most of the articles analysed sexuality in women less than 5 years after diagnosis because the emergence of sexual dysfunction is common and because certain treatments, such as chemotherapy, can lead to a reduction in physiological arousal of $15 \%$ and a reduction in sexual desire and lubrication of up to $64 \%$ (Broeckel et al., 2002; Herbenick et al., 2008; Vieira et al., 2013).

A study on the sexual function of 87 female breast cancer survivors after an average of 4,7 years from the start of treatment showed that women who received treatment longer than 5 years prior reported significantly $(p<0,05)$ less sexual pleasure than women who began treatment between 1-2 years or 2-5 years prior(Huguet et al., 2009).

Although it was not a focus of this review, mastectomy was demonstrated to be very prevalent in the analysed studies, and it was also an impactful factor in the sexual lives of women with breast CA.

It can be observed in the studies analysed in this review that mastectomy is related to the intimate, feminine and emotional aspects of women and is associated with problems related to body image (Jun et al., 2011; Panjari, Bell, \& Davis, 2011; Ueda et al., 2008). With regard to breast reconstruction and body image, a Japanese study compared groups of patients who underwent mastectomy, skin-sparing mastectomy or nipple-sparing mastectomy, accompanied by immediate breast reconstruction with women who underwent only radical mastectomy and women who underwent conservative breast surgery. Higher satisfaction and better body image were observed among those who underwent breast reconstruction and breast conservation, and less satisfaction and worse body image were observed in the radical mastectomy group (Biglia et al., 2010).

Thus, we can see how mastectomy is important to the body image and sexual activity of these women, who often feel incomplete and marginalized because the breast is synonymous with femininity.

From this review of the literature, it can be concluded that breast CA has a negative impact on various aspects of the sexual function of women affected by this disease, such as sexual desire, lubrication, pain and satisfaction. However, mastectomy also contributes negatively to the quality of the sexual lives of affected women.

\section{Conclusion}

The analysed studies also demonstrated that sexual dysfunction that arises from the diagnosis and treatment of breast CA can persist for years and can lead to psychological, physical and marital consequences, which affect the quality of life of these women.

Thus, we recognize the need for interventions that focus on the sexuality of women with breast CA, as this aspect is as important as others but is often overlooked by health professionals. Therefore, it is suggested that intervention research be conducted in this area in order to reduce cases of sexual dysfunction in this population.

\section{Competing Interests Statement}

The authors declare that there is no conflict of interests regarding the publication of this paper.

\section{References}

Abdo, C. (2004). Estudo da vida sexual do brasileiro. São Paulo, Bregantini.

Andersen, B. L. (2009). In sickness and in health: maintaining intimacy after breast cancer recurrence. Cancer journal (Sudbury, Mass.), 15(1), 70-73. https://doi.org/10.1097/PPO.0b013e318198c742

Barni, S., \& Mondin, R. (1997). Sexual dysfunction in treated breast cancer patients. Annals of Oncology, 8(2), 149-153. https://doi.org/10.1023/A:1008298615272

Biglia, N., Moggio, G., Peano, E., Sgandurra, P., Ponzone, R., Nappi, R. E., \& Sismondi, P. (2010). Effects of surgical and adjuvant therapies for breast cancer on sexuality, cognitive functions, and body weight. The journal of sexual medicine, 7(5), 1891-1900. https://doi.org/10.1111/j.1743-6109.2010.01725.x

Blumel, M. J. E., Binfa, E. L., Cataldo, A. P., Carrasco, V. A., Izaguirre, L. H., \& Sarrá, C. S. (2004). Indice de función sexual femenina: un test para evaluar la sexualidad de la mujer. Revista chilena de obstetricia y 
ginecología, 69(2), 118-125. https://doi.org/10.4067/S0717-75262004000200006

Brazil. Instituto Nacional de Câncer. (2011). Rastreamento organizado do câncer de mama: A experiência de Curitiba e a parceria com o Instituto Nacional de Câncer. Rio de Janeiro, INCA.

Brazil. Ministério da Saúde. Instituto Nacional de Câncer. (2014). Estimativas 2014: incidência de câncer no Brasil. Rio de Janeiro, Ministério da Saúde.

Brazil. Ministério da Saúde. Secretaria de Atenção à Saúde. Departamento de Atenção Básica. (2010). Saúde sexual e saúde reprodutiva. Brasília, Ministério da Saúde.

Broeckel, J. A., Thors, C. L., Jacobsen, P. B., Small, M., \& Cox, C. E. (2002). Sexual functioning in long-term breast cancer survivors treated with adjuvant chemotherapy. Breast cancer research and treatment, 75(3), 241-248. https://doi.org/10.1023/A:1019953027596

Cavalheiro, J. A. C., da Costa Bittelbrunn, A. C., Menke, C. H., Biazús, J. V., Xavier, N. L., Cericatto, R., ... \& Passos, E. P. (2012). Sexual function and chemotherapy in postmenopausal women with breast cancer. $B M C$ Women's Health, 12(1), 1-8. https://doi.org/10.1186/1472-6874-12-28

Drienssnack, N. M., Sousa, V. D., \& Mendes, I. A. C. (2007). An overview of research designs relevant to nursing: part 2: qualitative research designs. Rev Latino-am Enferm, 15(4), 684-648. https://doi.org/10.1590/S0104-11692007000400025

Ferreira, S. M. A., Panobianco, M. S., Gozzo, T. O., \& Almeida, A. M. (2013). A sexualidade da mulher com câncer de mama: análise da produção científica de enfermagem. Texto \& Contexto Enfermagem, 22(3), 835-843. https://doi.org/10.1590/S0104-07072013000300033

Fobair, P., \& Spiegel, D. (2009). Concerns about sexuality after breast cancer. The Cancer Journal, 15(1), 19-26. https://doi.org/10.1097/PPO.0b013e31819587bb

Herbenick, D., Reece, M., Hollub, A., Satins, S., \& Dodge, B. (2008). Young female breast cancer survivors: their sexual function and interest in sexual enhancement products and services. Cancer nursing, 31(6), 417-425. https://doi.org/10.1097/01.NCC.0000339252.91194.6c

Hill, K. A., Nadler, T., Mandel, R., Burlein-Hall, S., Librach, C., Glass, K., \& Warner, E. (2012). Experience of young women diagnosed with breast cancer who undergo fertility preservation consultation. Clinical breast cancer, 12(2), 127-132. https://doi.org/10.1016/j.clbc.2012.01.002

Holzner, B., Kemmler, G., Kopp, M., Moschen, R., Schweigkofler, H. R., Du Nser, M., ... \& Sperner-Unterweger, B. (2001). Quality of life in breast cancer patients not enough attention for long-term survivors? Psychosomatics, 42(2), 117-123. https://doi.org/10.1176/appi.psy.42.2.117

Huguet, P. R., Morais, S. S., Osis, M. J. D, Pinto-neto, A. M., \& Gurgel, M. S. C. (2009). Qualidade de vida e sexualidade de mulheres tratadas de câncer de mama. Revista Brasileira de Ginecologia e Obstetrícia, 31(2), 61-67. https://doi.org/10.1590/S0100-72032009000200003

Jun, E. Y., Kim, S., Chang, S. B., Oh K., Kang, H. S., \& Kang, S. S. (2011). The effect of a sexual life reframing program on marital intimacy, body image, and sexual function among breast cancer survivors. Cancer nursing, 34(2), 142-149. https://doi.org/10.1097/NCC.0b013e3181flab7a

Juraskova, I., Jarvis, S., Mok, K., Peate, M., Meiser, B., ... \& Cheah, B. C. (2013). The acceptability, feasibility, and efficacy (phase I/II study) of the OVERcome (Olive Oil, Vaginal Exercise, and MoisturizeR) intervention to improve dyspareunia and alleviate sexual problems in women with breast cancer. The journal of sexual medicine, 10(10), 2549-2558. https://doi.org/10.1111/jsm.12156

Kadmon, I., Ganz, F. D., \& Woloski-wruble, A. C. (2008). Social, marital, and sexual adjustment of Israeli men whose wives were diagnosed with breast cancer. Oncology nursing forum, 35(1), 131-135. https://doi.org/10.1188/08.ONF.131-135

Kedde, H., Van de wiel, H. B., Weijmar Schultz, W. C., \& Wijsen, C. (2013). Sexual dysfunction in young women with breast cancer. Support Care in Cancer, 21(1), 271-280. https://doi.org/10.1007/s00520-012-1521-9

Letourneau, J. M., Smith, J. F., Ebbel, E. E., Craig, A., Katz, P. P., Cedars, M. I., \& Rosen, M. P. (2012). Racial, socioeconomic, and demographic disparities in access to fertility preservation in young women diagnosed with cancer. Cancer, 118(18), 4579-4588. https://doi.org/10.1002/cncr.26649 
Lewis, R. W., Fugl - Meyer, K. S., Bosch, R., Fugl - Meyer, A. R., Laumann, E. O., Lizza, E., \& Martin - Morales, A. (2004). Epidemiology/risk factors of sexual dysfunction. The journal of sexual medicine, 1(1), 35-39. https://doi.org/10.1111/j.1743-6109.2004.10106.x

Moura, F. M. J. S. P., Silva, M. G., \& Oliveira, S. C. (2010). Os sentimentos das mulheres pós-mastectomizadas. Esc Anna Nery, 14(3), 477-484. https://doi.org/10.1590/S1414-81452010000300007

Pablo, C., \& Soares, C. (2004). As disfunções sexuais femininas. Revista Portuguesa de Medicina Geral e Familiar, 20(3), 357-370. Retrieved from http://rpmgf.pt/ojs/index.php/rpmgf/article/view/10044/9781

Panjari, M., Bell, R. J., \& Davis, S. R. Sexual function after breast cancer. The journal of sexual medicine, 8(1), 294-302. https://doi.org/10.1111/j.1743-6109.2010.02034.x

Pinto, A. C. S., Luna, I. T., Silva, A. A., Pinheiro, P. N. C., Braga, V. B., \& Souza, A. M. A. (2014). Fatores de risco associados a problemas de saúde mental em adolescentes: revisão integrativa. Revista da Escola de Enfermagem da USP, 48(3), 555-564. https://doi.org/10.1590/S0080-623420140000300022

Rashidi, S., \& Dashti, F. (2016). Sexual behavior pattern and related factors in women with breast cancer in Iran. Global Journal of Health Science, 8(7), 226-272. https://doi.org/10.5539/gjhs.v8n7p266

Ribeiro, B., Magalhaes, A. T., \& Mota, I. (2013). Disfunção sexual feminina em idade reprodutiva: prevalência e fatores associados. Revista Portuguesa de Medicina Geral e Familiar, 29(1), 16-24. Retrieved from http://www.scielo.mec.pt/scielo.php?script=sci_arttext\&pid=S2182-51732013000100004\&lng=pt.

Sadovsky, R., Basson, R., Krychman, M., Morales, A. M., Schover, L., Wang, R., \& Incrocci, L. (2010). Cancer and sexual problems. The journal of sexual medicine, 7(1pt2), 349-373. https://doi.org/10.1111/j.1743-6109.2009.01620.x

Safarinejad, M. R., Shafiei, N., \& Safarinejad, S. (2013). Quality of life and sexual functioning in young women with early-stage breast cancer 1 year after lumpectomy. Psycho-oncology, 22(6), 1242-1248. https://doi.org/10.1002/pon.3130

Santos, D. B., \& Vieira, E. M. Imagem corporal de mulheres com câncer de mama: uma revisão sistemática da literatura. Ciência \& Saúde Coletiva, 16(5), 2511-2522. Retrieved from http://producao.usp.br/handle/BDPI/7756

Sbitti, Y., Kadiri, H., Essaidi, I., Fadoukhair, Z., Kharmoun, S., Slimani, K., ... \& Errihani, H. (2008). Breast cancer treatment and sexual dysfunction: Moroccan women's perception. BMC Womens Health, 11(1), 29. https://doi.org/10.1186/1472-6874-11-29

Takahashi, M., Ohno, S., Inoue, H., Kataoka, A., Yamaguchi, H., Uchida, Y., ... \& Kai, I. (2008). Impact of breast cancer diagnosis and treatment on women's sexuality: a survey of Japanese patients. Psycho-Oncology, 17(9), 901-907. https://doi.org/10.1002/pon.1297

Thiel, R. R. C., Dambros, M., Palma, P. C. R., Thiel, M., Ricceto, C. L. Z., \& Ramos, M. F. (2008). Tradução para o português, adaptação cultural e validação do Female Sexual Function Index. Revista Brasileira de Ginecologia e Obstetrícia, 30, 504-510. https://doi.org/10.1590/S0100-72032008001000005

Ueda, S., Tamaki, Y., Yano, K., Okishiro, N., Yanagisawa, T., Imasato, M., ... \& Taguchi, T. (2008). Cosmetic outcome and patient satisfaction after skin-sparing mastectomy for breast cancer with immediate reconstruction of the breast. Surgery, 143(3), 414-425. https://doi.org/10.1016/j.surg.2007.10.006

Vieira, E. M., Júnior, G. H. Y., Souza, H. C. C., Mancini, M. P. M., \& Perdoná, G. S. C. (2013). História reprodutiva e sexual de mulheres tratadas de câncer de mama. Revista Brasileira de Ginecologia e Obstetrícia, 35(2), 78-83. https://doi.org/10.1590/S0100-72032013000200007

Whittemore, R., Knafl, K. (2005). The integrative review: updated methodology. Journal of advanced nursing, 52(5), 546- 553. https://doi.org/10.1111/j.1365-2648.2005.03621.x

Yang, E. J., Kim, S. W., Heo, C. Y., \& Lim, J. Y. (2011). Longitudinal changes in sexual problems related to cancer treatment in Korean breast cancer survivors: A prospective cohort study. Support Care in Cancer, 19(7), 909-918. https://doi.org/10.1007/s00520-010-0885-y 


\section{Copyrights}

Copyright for this article is retained by the author(s), with first publication rights granted to the journal.

This is an open-access article distributed under the terms and conditions of the Creative Commons Attribution license (http://creativecommons.org/licenses/by/4.0/). 